\title{
A SYSTEM FOR STATE-OF-HEALTH DIAGNOSIS OF LEAD-ACID BATTERIES INTEGRATED WITH A BATTERY CHARGER
}

\author{
Telles B. Lazzarin ${ }^{1}$ and Ivo Barbi ${ }^{2}$ \\ ${ }^{1}$ Federal Institute of Santa Catarina (IFSC), Florianópolis - SC, Brazil \\ ${ }^{2}$ Federal University of Santa Catarina (UFSC), Florianópolis - SC, Brazil \\ e-mails: telles@inep.ufsc.br, ivobarbi@inep.ufsc.br
}

\begin{abstract}
This paper reports a theoretical and experimental study on a proposal for a lead-acid battery charger applied in UPS, which has an integrated on-line test system to determine the state-of-health $(\mathrm{SoH})$ of the batteries. The charger control structure is designed to ensure an appropriate charge for every battery in the pack. The battery evaluation system is based on historical analysis of the periodic measurements, such as internal impedance, DC voltage and operation temperature, performed for each battery. The periodic monitoring of these parameters provided by the integration of systems eliminates the disadvantages of online tests and thus allows the user to analyze the batteries adequately. The structure was experimentally verified on a prototype, where the battery SoH diagnosis system was integrated with a $1.5 \mathrm{~kW}$ battery charger. The system was designed for a bank of sixteen batteries associated in series.
\end{abstract}

Keywords - Battery Charger, Impedance Measurement, Stage-of-Health, Lead-Acid Battery.

\section{INTRODUCTION}

The stationary lead-acid batteries commonly employed in Uninterrupted Power Supplies (UPSs) need to be in an adequate state to ensure that the required power is available. A lead-acid battery under appropriate conditions of use has a useful life of around three to four years, according to manufacturers. However, there are two kinds of problems associated with these batteries: the first originates from an insufficient recharging process, which will eventually lead to a capacity reduction of the battery pack; and the second, more serious, problem is related to several factors such as inappropriate voltage levels, temperature offsets, deep discharges and the electrode sulfating process which, either acting alone or together, can cause reductions of over $50 \%$ in the battery life.

Thus, when critical loads are fed to a battery pack, a periodic evaluation of this bank needs to be carried out in order to ensure system reliability. The traditional capacity test [1] requires a full pack discharge. This method has the disadvantages of taking a long time, being performed off-line and requiring the battery to be submitted to a charge/discharge cycle. To address these issues, for the past 20 years research has been carried out in order to find ways to evaluate the $\mathrm{SoH}$ (state-of-health) of batteries while they are connected to their respective charging system (on-line tests) [2-22]. Techniques based on impedance [2], resistance $[13,14]$ and conductance $[4,21,22]$ measurements are

Manuscript received 02/07/2011; fisrt review 03/01/2012; second review $23 / 02 / 2012$. Accepted for publication $24 / 02 / 2012$ by recommendation of the Editor João Onofre Pereira Pinto. currently being investigated in order to obtain an on-line procedure for evaluating the batteries. These techniques provide the advantages of increasing the reliability of the system, reducing its aging and decreasing the maintenance costs.

One of the methodologies under study, which has shown good results, is the impedance method [2]. This consists of injecting an alternating current into the accumulator to measure the alternating voltage drop component. The impedance is calculated through these measurements, in the injected current frequency bandwidth. The impedance increases as the $\mathrm{SoH}$ deteriorates [2, 3, 14]. Moreover, studies also show that the impedance module resembles the battery internal impedance; therefore one can analyze only the module. This strategy is appropriate for packs where the batteries are connected in series, because the measurement system is simplified due to the fact that there is only one path for the AC current. Since this is the typical arrangement of batteries employed in UPSs, the impedance test is adequate for this application.

Previous studies have shown that the increase of $30 \%$ compared with the original impedance in a battery is correlated to the decrease in the charge capacity to around $80 \%$ of the initial value $[2,3,9,10,14]$. At this value the battery is considered damaged (end of its useful life) [1].

However, the results presented in $[2,4,6]$ show that the battery impedance varies with its capacity, temperature, charge level and frequency. Therefore, the battery temperature and charge level also need to be monitored and the on-line test must always be carried out under the same charge conditions, preferably at a charge level of close to $100 \%$. It is also necessary to select a frequency, or a band of frequencies, at which the behavior was previously known in order to correctly perform the impedance measurements. Due to these characteristics, it is difficult to analyze and determine the $\mathrm{SoH}$ of a battery based on a single internal impedance measurement.

In this context, this paper proposes an on-line system for $\mathrm{SoH}$ diagnosis of batteries based on an impedance method. With the aim of eliminating the disadvantages of the traditional impedance test, the proposal of this study is to integrate the measurer to the battery charger, as shown in Figure 1. The main goal is to obtain a periodic battery analyzer that retains these periodically-measured values, allowing the SoH of the battery to be diagnosed through comparisons and the analysis of historical measurements. Furthermore, the integrated system ensures that the batteries are only evaluated during float operation.

Besides impedance monitoring, measurements of the DC voltages and of the operating temperature of the batteries are also carried out. The aim of the DC voltage measurements is 
to identify problems related to short-circuit, connection and charge level. These temperature measurements are used to evaluate the impedance measurements, due to the fact that the temperature can also cause an increase in the battery internal resistance $[2,4,6]$. Therefore, the system to evaluate the $\mathrm{SoH}$ of a battery must be based on the historical data obtained from all of these measurements, which increases the effectiveness of the proposed system.

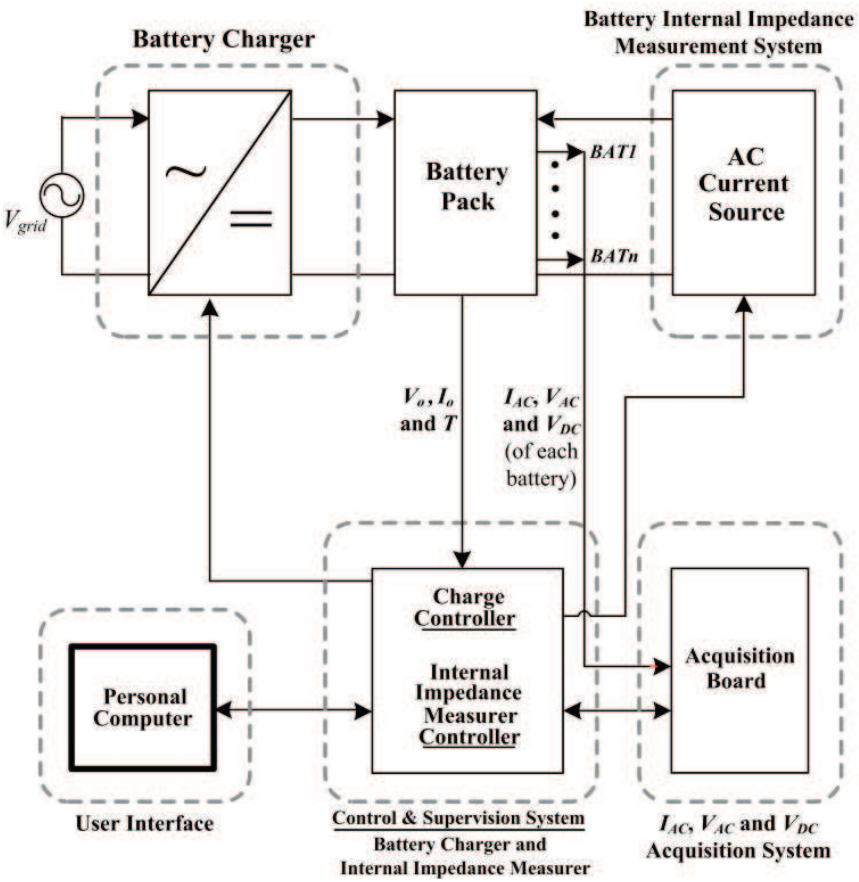

Fig. 1. Block diagram of the proposed system.

\section{SYSTEM DESCRIPTION}

The proposed system consists of a battery charger with the following characteristics: a charging algorithm that reaches the bulk voltage, guaranteeing that the batteries are $100 \%$ recharged; floating voltage reference compensation due to temperature offsets, preventing insufficient recharge, irreversible sulfating and premature corrosion of the positive grating; sulfation protection, applying the recharging of the pack every 6 months, even when fully charged, using the bulk voltage to promote the electrolyte mixture. The sulfation problem can occur when the batteries are held for long periods under the same charge state. Each one of these characteristics aims to optimize the useful life of the battery.

In addition to the charger, a circuit to evaluate the $\mathrm{SoH}$ of the batteries through measuring their impedance, DC voltage and temperature is also proposed. These measurements will be taken periodically and kept in the microcontroller until the user connects to the system, through a PC (Personal Computer), and downloads the data for further analysis, as shown in Figure 1.

When placing together the impedance measurer and the battery charger, one can make periodic checks and obtain a reliable analysis of the $\mathrm{SoH}$ of the batteries. With the database created throughout the use of the equipment it is possible to investigate the variation in the impedance and not only its magnitude. This study gives special attention to the battery evaluation system. However, the power and control circuits of the charger also are designed using traditional methodologies.

\section{BATTERY EVALUATION SYSTEM}

The proposed battery evaluation system consists of a circuit with impedance, DC voltage and temperature measurers. The impedance circuit measurer injects and measures an alternating current $\left(I_{C A}\right)$ in the battery pack, measures the alternating voltage drop caused on each battery $\left(V_{A C_{-} B A T x}\right)$ and, based on the voltage and current values, calculates the battery impedance module $\left(Z_{B A T x}\right)$ at the frequency of the injected current, as illustrated in Figure 2 and defined in (1). The proposed system evaluates the battery impedance at a single frequency, which can be the frequency of the electrical grid.

In order to verify possible problems such as bulk voltage, insufficient recharge, sulfation and short circuiting in the battery cells, the DC voltage $\left(V_{D C B A T n}\right)$ in each accumulator is measured, as also illustrated in Figure 2.

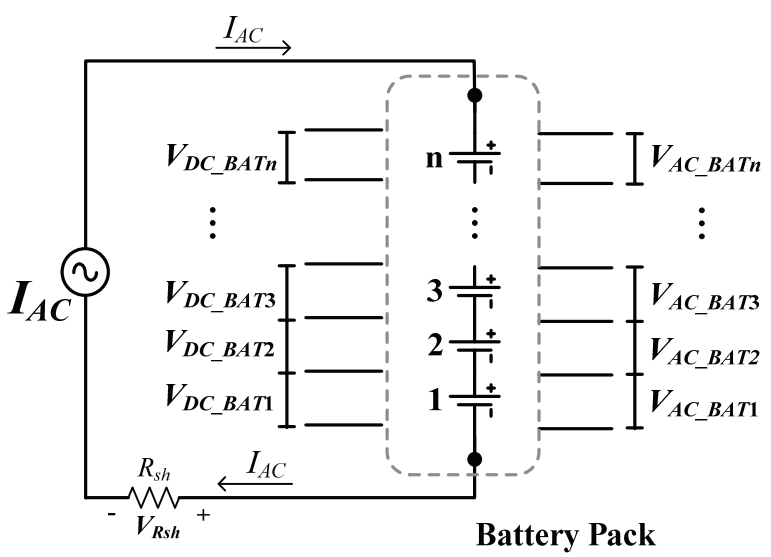

Fig. 2. Battery evaluation system.

$$
Z_{B A T x}=\frac{V_{A C_{-} B A T x}}{I_{A C}}
$$

\section{A. AC Current Source Design}

The proposed circuit of the AC current source is shown in Figure 3. It has undergone some modification in comparison to its original version published in [9]. The circuit applies an AC current of $50 \mathrm{~Hz}$ or $60 \mathrm{~Hz}$ to the battery pack. Therefore, the fed voltage $V_{i n}$ can come from the electricity grid. The $V_{\text {in }}$ voltage is defined in (2). The circuit of Figure 3 has a transformer $\left(T_{1}\right)$, which is responsible for the electric isolation and adjusts the level of the $V_{2}$ voltage. The circuit uses a capacitor $\left(C_{1}\right)$ connected in series between the secondary winding and the battery pack. The objective is to block the DC current component and limit the AC current component $\left(I_{A C}\right)$ that is being injected into the battery pack. The diode $D_{1}$ is employed only to protect the electrolytic capacitor $C_{1}$. It does not take part in the normal operation of the circuit.

Injection of the AC current $\left(I_{A C}\right)$ into batteries only occurs when the secondary winding is connected in series with the capacitor $C_{1}$ and the battery pack $\left(V_{B A T}\right)$. This is carried out changing the $S_{1}$ position of "2" to "1", as illustrated in Figure 3. 


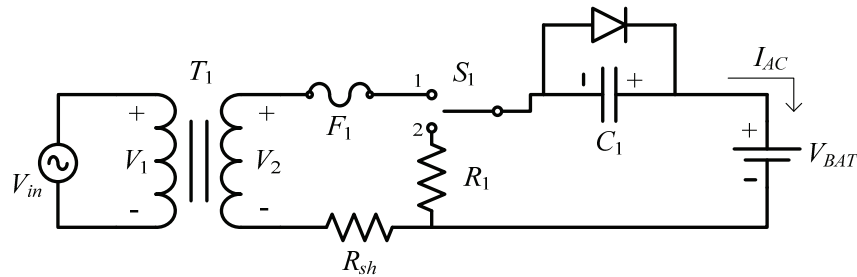

Fig. 3. Electric circuit proposed for the AC current source.

$$
V_{\text {in }}=V_{1} \cdot \sin (\omega \cdot t)
$$

When the AC current injection is off, the $S_{1}$ relay is in position "2". In this case, the circuit has a high electrical resistance $\left(R_{1}\right)$ value when connected in series with the capacitor $C_{1}$ and the battery pack $\left(V_{B A T}\right)$. Thus, $C_{1}$ is precharged with $V_{B A T}$ voltage while the switch $S_{1}$ remains at position " 2 ". This strategy decreases the transient in the circuit when the position of the $S_{1}$ relay changes from "2" to "1".

The analytical study of the circuit presented in Figure 3 shows that the current source behavior is described by means of equation (3), which is also used to find the peak value of the AC current injected into the battery pack. In (3), $L_{T 1}$ is the transformer leakage, $V_{2}$ is the voltage peak, $C_{1}$ is the capacitor value, $\omega$ is the frequency and $t$ is the time.

$$
I_{A C}=C_{1} \cdot \frac{V_{2} \cdot \omega}{\left(1-(\omega)^{2} \cdot L_{T 1} \cdot C_{1}\right)} \cdot \cos (\omega \cdot t)
$$

\section{B. Acquisition Circuit Design}

The technique used to measure the internal impedance of the batteries relies on an adequate circuit to measure the AC current and $\mathrm{AC}$ voltage components of each battery. Besides these two procedures the measurement of the DC voltages, aiming to monitor the individual voltage of each accumulator, as well as the operation temperature of the battery pack is also carried out.

A difficulty encountered in these acquisitions is the low AC voltage levels to be measured, due to the low internal resistance, and the high voltage offset of the batteries, because of their series connection. Moreover, the AC voltage is overlapped with the DC voltage of each battery.

The acquisition circuit considered in this study can be split into five parts as shown in Figures 4 to 8.

The first, as seen in Figure 4, is composed of a set of resistive dividers (gain), a differential MUX (multiplexer) and two voltage followers (used as buffers). As the batteries are connected in series, a differential MUX is employed to select one battery and measure its voltage. The output signal at this stage is the differential voltage between " $V_{\text {out }}+$ " and " $V_{\text {out }}{ }^{-"}$.

Two parts of the acquisition circuit are used to acquire the necessary signals from " $V_{\text {out }}+$ " and " $V_{\text {out }}$ ", these being the $\mathrm{DC}$ and $\mathrm{AC}$ voltage components of the batteries. Figure 5 shows the block diagram of the stage used to obtain the DC voltage $\left(V_{D C}\right)$ of the battery. It comprises a circuit to measure the differential voltage of the first output stage, a low-pass filter with a cutoff frequency of $30 \mathrm{~Hz}$ to block $\mathrm{AC}$ components and a gain stage to adapt the output signal.

The structure used to measure the $\mathrm{AC}$ voltage $\left(V_{A C}\right)$ is detailed in the block diagram in Figure 6. It has a circuit to block the DC voltage component, a stage to measure the differential AC voltage in the battery, a low-pass filter with a cutoff frequency of $600 \mathrm{~Hz}$ to eliminate high-frequency noise, a precision rectifier that changes the negative cycle of the sinusoidal signal into a positive cycle (rectifier) and, finally, a gain stage to adapt the output signal.

The fourth part of the acquisition circuit is used to acquire the AC current injected into the bank. It measures the drop voltage at a shunt resistor $\left(R_{s h}\right)$ that is placed in the source circuit, as shown in Figure 3. The output signal at this stage is $V_{I A C}$. The structure to measure the AC current can be seen in Figure 7. It has a stage to measure the differential voltage in $R_{s h}$, a low-pass filter with a cutoff frequency of $600 \mathrm{~Hz}$ to eliminate high-frequency noise, a precision rectifier that also changes the negative cycle of the sinusoidal signal into a positive cycle and a gain stage.

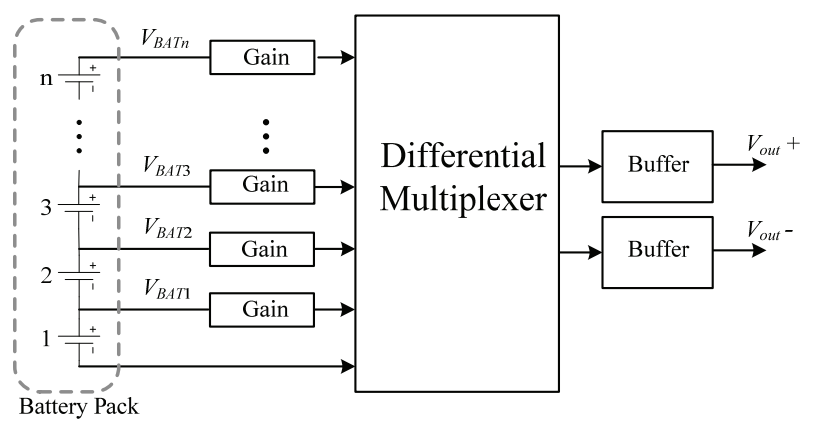

Fig. 4. Circuit responsible for selecting a battery for evaluation.

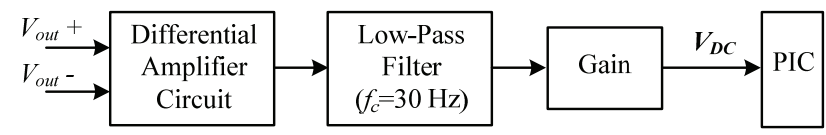

Fig. 5. Acquisition circuit diagram employed to measure the DC voltage.

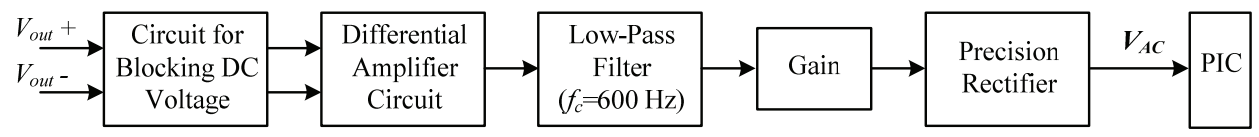

Fig. 6. Acquisition circuit diagram employed to measure the AC voltage.

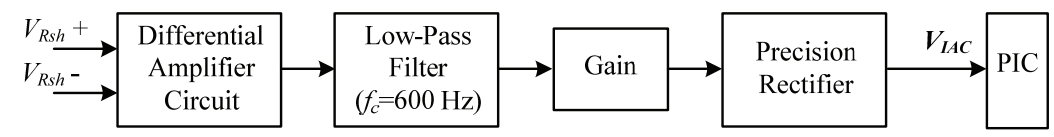

Fig. 7. Acquisition circuit diagram employed to measure the AC current. 
The rectifiers in Figures 6 and 7 and are needed because the microprocessor (PIC) employed in signal processing reads only positive values.

Finally, the circuit diagram designed to measure the operation temperature of the battery pack is shown in Figure 8. It employs an NTC (negative temperature coefficient) sensor that is placed on the battery pack and a gain stage.

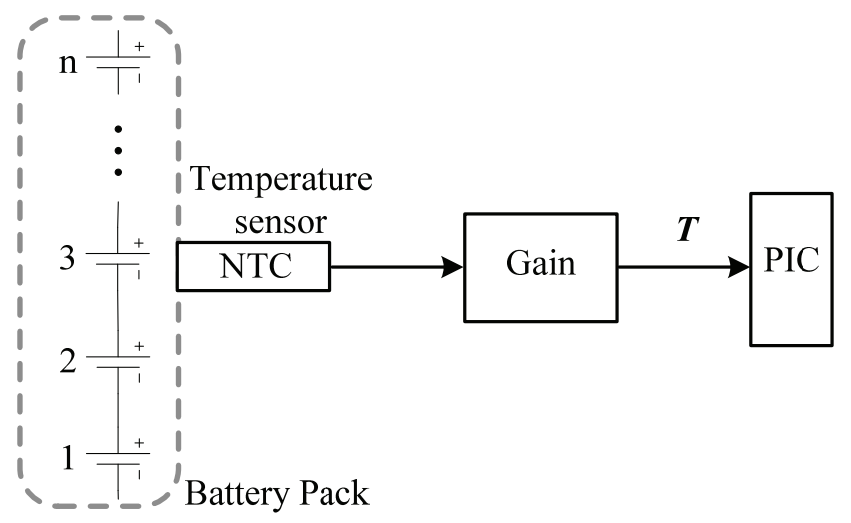

Fig. 8. Acquisition circuit diagram employed to measure the battery pack temperature.

\section{Monitoring System}

The battery charger monitoring is carried out through the Microchip ${ }^{\circledR}$ microcontroller $\operatorname{PIC}^{\circledR} 18 \mathrm{~F} 4331$. The block diagram presented in Figure 9 gives an overview of the monitoring system created with the PIC to control the battery charging algorithm, impedance evaluation system, serial communication with the PC and user interface.

The main function of the microcontroller is to control the system when performing a battery evaluation routine. This can occur in two ways: one through an internal clock implemented through a PIC timer, which prompts the system to make the measurements; and the other by means of a button in which the user, when required, can request the battery analysis. The measurements will only be made if the batteries are fully charged. This means that the charger must be in the maintenance voltage stage, holding the voltage $V_{b a t}$ at the float level, and the batteries with the maintenance current. It is proposed that these measurements are automatically made on a weekly basis. This period considers an average battery useful life of around 3 to 4 years and that its $\mathrm{SoH}$ does not change significantly within one week.

During the impedance measurements the system disables the charger power stage, switching off $S_{1}$, detaching the charger from the batteries. $S_{2}$ closes to inject the AC current into the battery pack and the PIC determines which battery must be evaluated, takes the DC voltage $\left(V_{D C}\right)$, AC voltage $\left(V_{A C}\right)$, AC current $\left(V_{I A C}\right)$, temperature $(\mathrm{T})$ measurements and stores the values in its EEPROM (Electrically Erasable Programmable Read Only Memory).

The EEPROM memory is non-volatile, thus it retains the data avoiding information losses during an unexpected system disconnection. On completing the measurements, the PIC releases the battery charger again. With the stored $\mathrm{AC} / \mathrm{DC}$ voltages and $\mathrm{AC}$ current measurements, the microcontroller estimates the impedance of each battery and performs a quick test. Thus, it can warn the user if it registers a significant change in the system.

The stored measurements of voltage and current are then sent to a computer, where a dedicated program calculates the impedance accurately. This program saves the values to retain a historical record of the measurements for each battery.

The impedance reference value for each battery of the bank, used in the calculation of the normalized impedance and in the evaluation of its $\mathrm{SoH}$, must be obtained from the measured data.

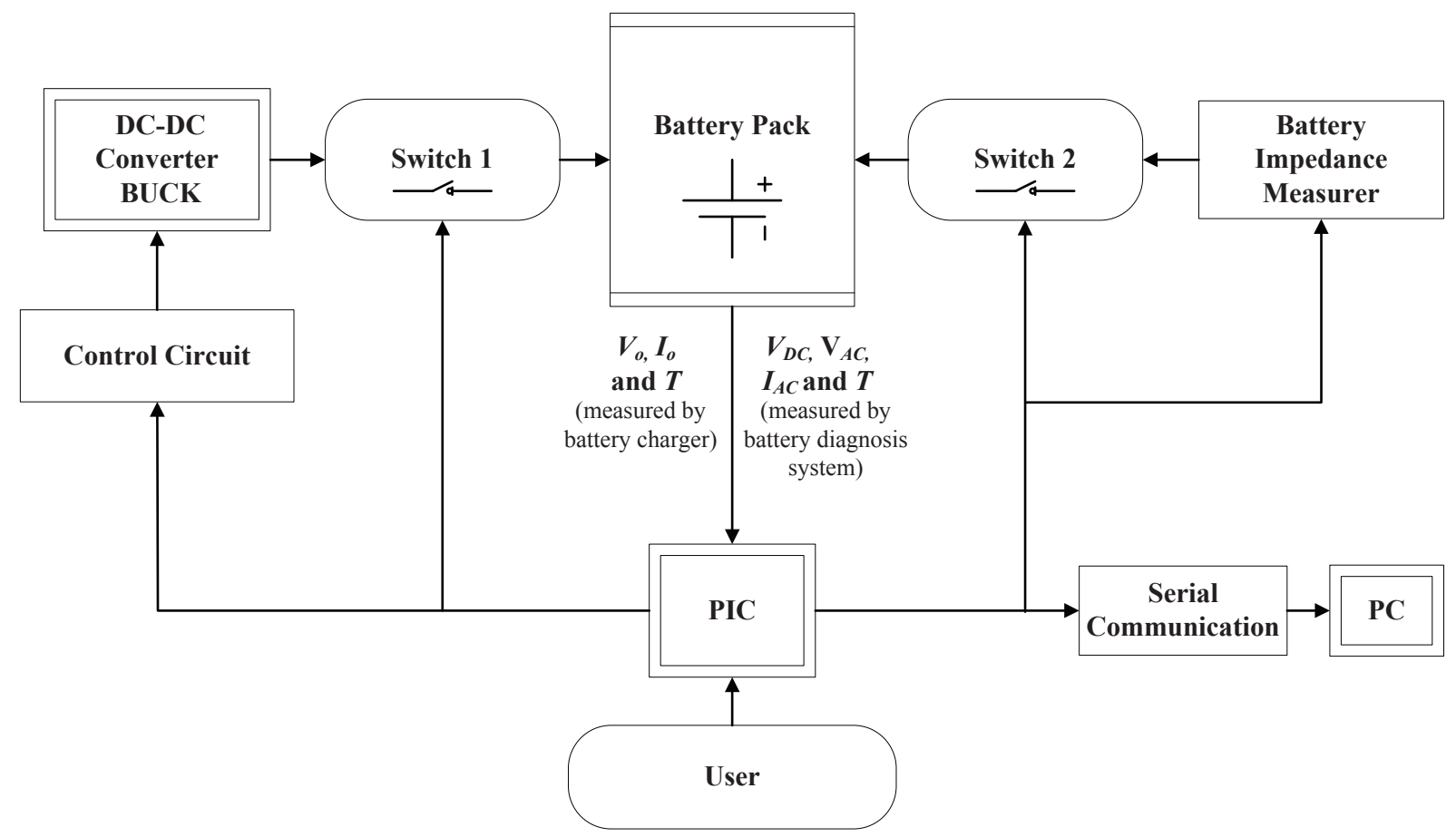

Fig. 9. Block diagram of the proposed monitoring system. 
In this study, it is proposed that each battery employs its own impedance value, measured when the battery is new, as a reference to evaluate its $\mathrm{SoH}$. Therefore, in the control algorithm, created when the battery is new or right after the first charge cycle, the battery is submitted to at least twenty impedance measurements, sequentially and under the same charge conditions. The average of these impedance measurements is used as the reference value. This is necessary because there are significant differences between the individual battery impedances. This strategy eliminates a major problem associated with impedance testing, which is to define an adequate reference value to evaluate the battery impedance. Furthermore, this is easily achieved in this system due to the fact that the evaluation circuit was integrated with the battery charger and these measurements can be carried out when installing the battery pack.

\section{EXPERIMENTAL RESULTS}

The initial experimental results were obtained by performing an investigation to verify the methodology of the impedance test and the impedance frequency response of lead-acid batteries. The tests consisted of injecting an alternating current of $5 \mathrm{~A}$, from $10 \mathrm{~Hz}$ to $1000 \mathrm{~Hz}$, into three batteries of 12V@36Ah, each under different SoH. The accumulators were designated as $\mathrm{A}, \mathrm{B}$ and $\mathrm{C}$, where $\mathrm{A}$ represents new, $\mathrm{B}$ is bad $\mathrm{SoH}$ (end of its useful life) and $\mathrm{C}$ is totally damaged (sulfation problem and short-circuit in the cells).

Figure 10 shows the impedance modules for the three batteries. Battery A has the smallest value across the whole frequency range. The accumulator $\mathrm{B}$ has an impedance around $50 \%$ to $80 \%$ higher than battery A (depending on the frequency). Battery $\mathrm{C}$ (totally damaged) has a much higher impedance value when compared to the other two. However, the impedance phases, presented in Figure 11, do not change with the deterioration of the battery SoH.

The behavior seen in Figures 10 and 11 verifies that the reduction in the battery $\mathrm{SoH}$ (or its capacity) causes an increase in the battery impedance module. These test results strengthen the performance of the impedance technique, since the internal impedance of the battery varies with a deteriorating $\mathrm{SoH}$, and this phenomenon can be monitored through the impedance module. The figures also demonstrate that in the range of $40 \mathrm{~Hz}$ to $600 \mathrm{~Hz}$ it is possible to evaluate the battery at a single frequency, because the modules increase and the phases remain constant when the battery reduces its capacity. This range of frequency is valid for this type of battery.

After the experimental investigation of the impedance test methodology a prototype was built in which the battery $\mathrm{SoH}$ diagnosis system was integrated with the battery charger. A photograph of the prototype can be seen in Figure 12. The proposed system was verified in a lead-acid battery bank employed in UPSs.

The system to determine the $\mathrm{SoH}$ is composed of an $\mathrm{AC}$ current source, an acquisition circuit and a supervision system, as proposed in section III. The AC current source was designed to supply an AC current of $4 \mathrm{~A}$ and $60 \mathrm{~Hz}$ to the batteries. Thus, the batteries are evaluated through the impedance measurements carried out at a single frequency
$(60 \mathrm{~Hz})$. The acquisition circuit was designed to measure the $\mathrm{AC}$ and $\mathrm{DC}$ voltages in all batteries, the $\mathrm{AC}$ current injected into bank and the operation temperature. The circuit monitoring is carried out through a PIC, which controls the operation modes of the system, stores the measurements and sends the data to the PC.

The battery charger was designed for a current capacity of the up to $8 \mathrm{~A}$. It was connected to a battery pack bank with sixteen accumulators associated in series (each battery was of 12V@36Ah), resulting in a 192V DC link. The power circuit of the battery charger is composed of a rectifier and a Buck converter. The control circuit employs the CI bq2031 of UNITRODE. The battery charger circuits were designed using tradition methodologies.

The recharge current was set to $4.5 \mathrm{~A}$ due to the capacity of the batteries. When initiating the test, the battery pack presented a voltage of $180 \mathrm{~V}$. The voltage and the load current behaviors during the recharge process are shown in Figures 13 and 14, respectively. During the recharge process the battery voltage pack reaches the equalization voltage $(235 \mathrm{~V})$ and ends at the float voltage $(216 \mathrm{~V})$. The recharger sustains a small load maintenance current.

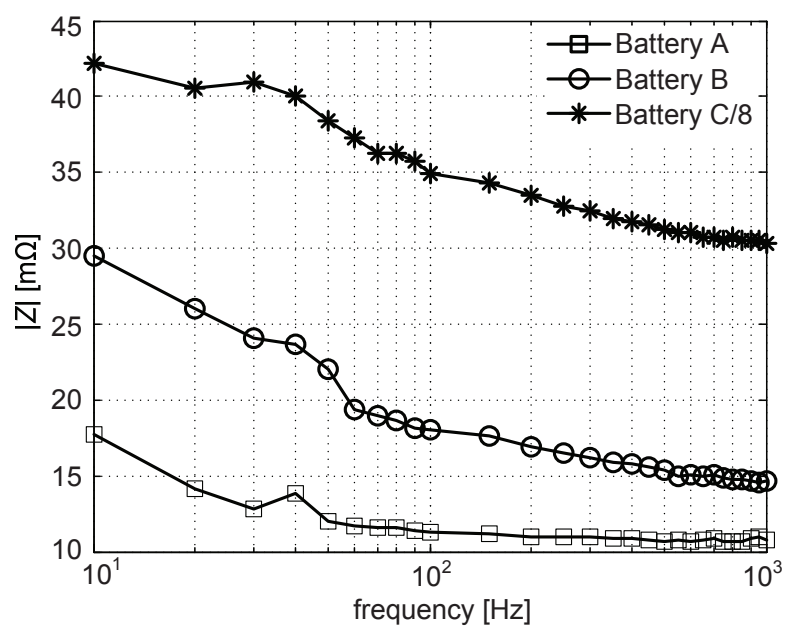

Fig. 10. Battery impedance module.

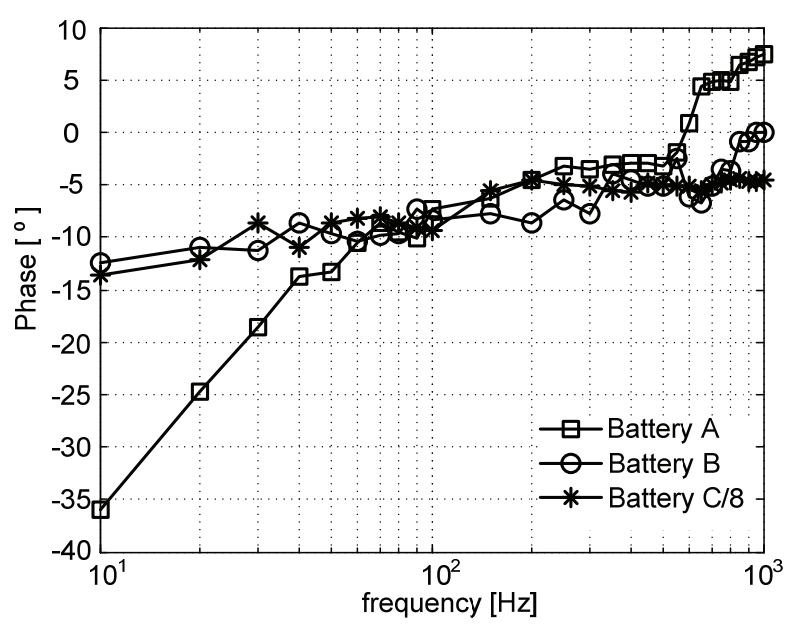

Fig. 11. Battery impedance phase. 


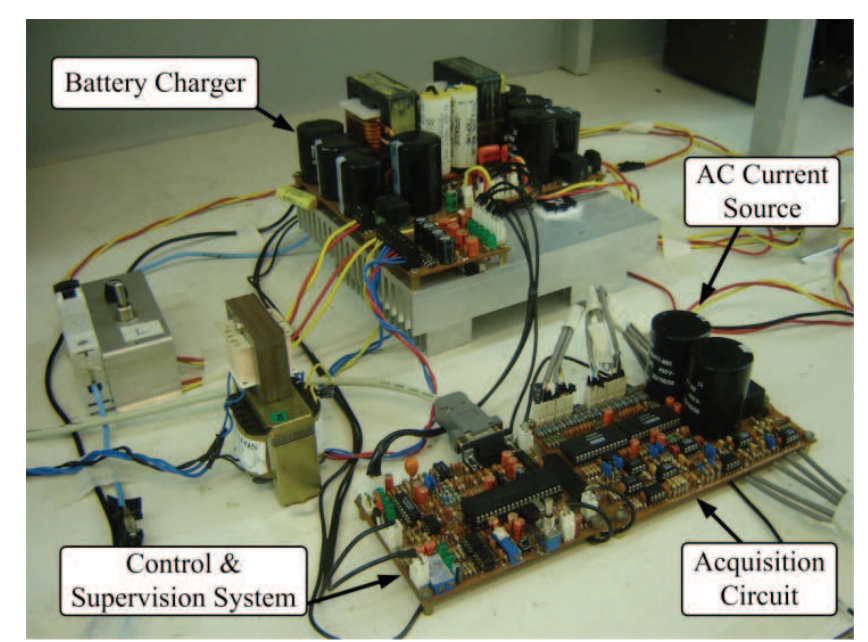

Fig. 12. Photograph of the prototype.

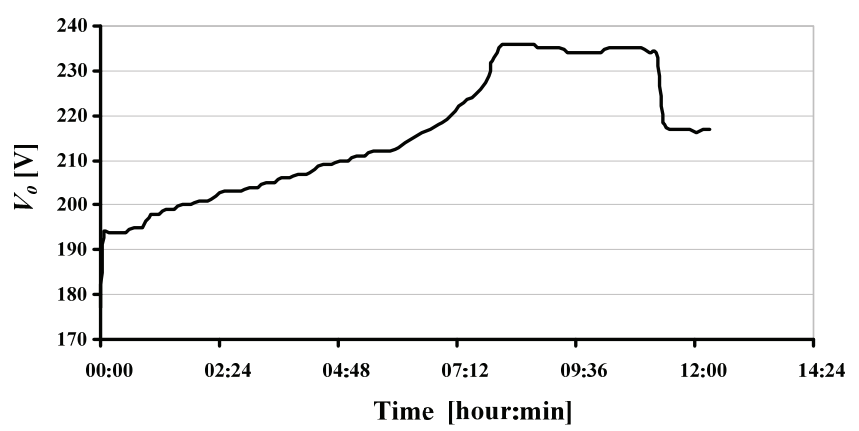

Fig. 13. Battery pack voltage during recharge process.

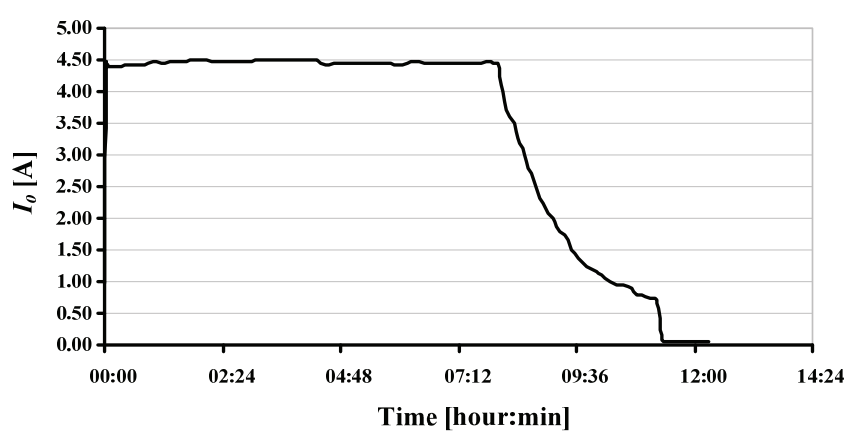

Fig. 14. Charge current of battery pack during recharge process.

Fifty measurements of the bank of batteries were taken to evaluate the $\mathrm{SoH}$ of the batteries, in a period of three months. The main goal of these measurements was to validate the proposed battery evaluation system. These preliminary results are shown in Figures 15 to 20. A complete analysis to confirm the capacity of the proposed system to perform a $\mathrm{SoH}$ diagnosis of batteries requires the monitoring of a complete battery life cycle, which is around three to four years.

Figure 15 shows the current injected into the battery bank and the $\mathrm{AC}$ voltage drop in battery 1 as the analysis was performed. Note that an AC current of 4.7 A causes an AC voltage drop in battery 1 of the order of millivolts.

Figure 16 presents the resulting signals obtained by the proposed acquisition system during the same analysis as that of Figure 15. The signals seen in Figure 16 are voltage levels proportional to the monitored variables. These are read by the ADC (analog-to-digital converter) of the PIC and converted into digital signals. The ADC of the PIC only takes readings of positive values and, thus, the $\mathrm{AC}$ signals are rectified in the acquisition circuit, as seen in Figures 6 and 7. The measured values for the DC voltage $\left.V_{D C(B A T 1)}\right)$, the AC current $\left(V_{I A C(B A T 1)}\right)$ and AC voltage $\left(V_{A C(B A T 1)}\right)$ of battery 1 are shown in Figure 16. Note that the values measured are of the order of millivolts, as shown in Figure 15. However, the proposed acquisition system provides signals with low noise and appropriate quality for the PIC.

The results for fifty impedance measurements of batteries $1,2,3,4$ and 16 in the bank are presented in Figure 17 (magnitude) and Figure 18 (normalized value). The former shows that even when using batteries of the same brand/model/capacitance, the impedance values vary from $6.5 \mathrm{~m} \Omega$ to $9.5 \mathrm{~m} \Omega$, that is, by around $31 \%$. This strengthens the ability of the proposal system to analyze the battery SoH based on the impedance normalized value, as introduced in Figure 18.

The measurement results for the DC voltage, also for batteries 1, 2, 3, 4 and 16, are shown in Figure 19. It can be seen that there is a variation of around 60 millivolts, which shows that the batteries were evaluated under the same charge state [1] [2].

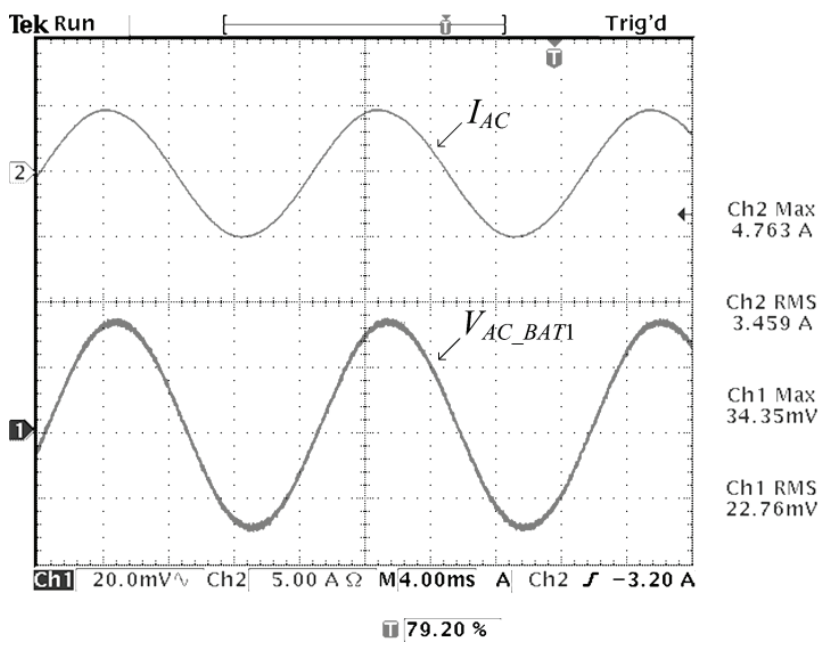

Fig. 15. AC current $\left(I_{A C}\right)$ injected into the battery pack and the $\mathrm{AC}$ voltage component of battery $1\left(V_{A C_{-} B A T 1}\right)$.

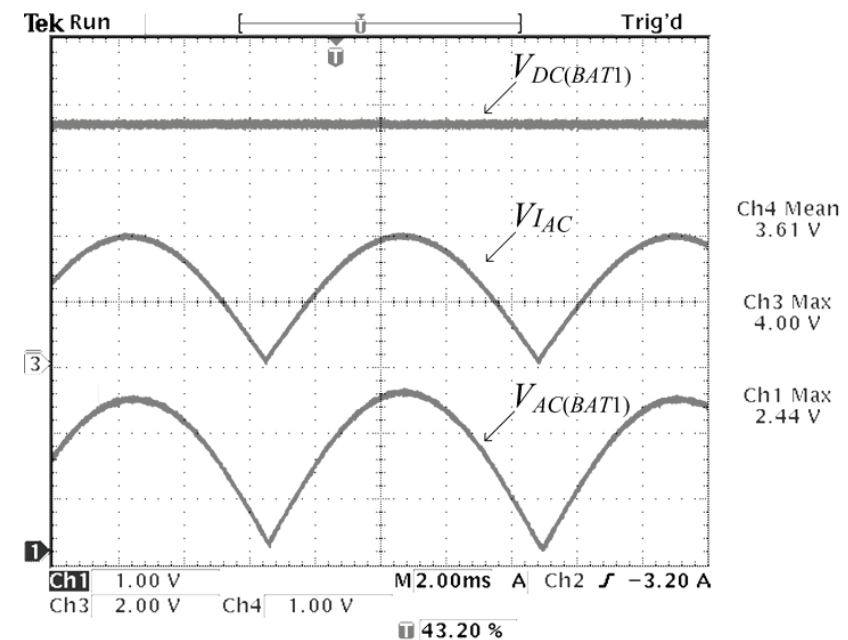

Fig. 16. Measurements taken in battery 1 employing the proposed acquisition system. DC voltage $\left(V_{D C(B A T 1)}\right)$, AC current $\left(V_{I A C}\right)$ and AC voltage $\left(V_{A C(B A T 1)}\right)$. 
The temperature measurements taken during the tests are given in Figure 20, which show a variation of around $1{ }^{\circ} \mathrm{C}$. Batteries were evaluated around the same bias point, therefore, the temperature did not influence the impedance values presented in Figures 17 and 18. However, during the life of the batteries, which is around three to four years, there will be situations of temperature variation and its monitoring will help in the diagnosis of battery SoH.

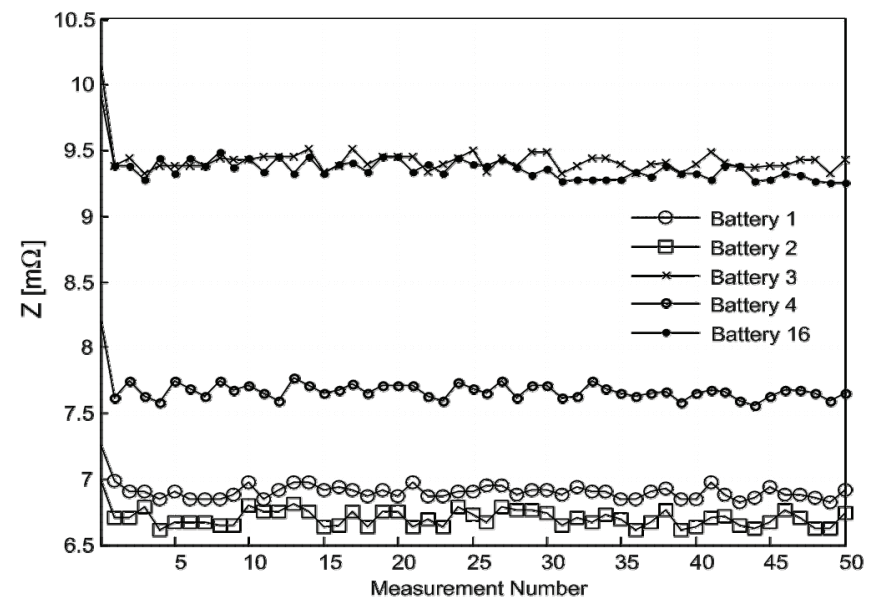

Fig. 17. Impedance module measurements.

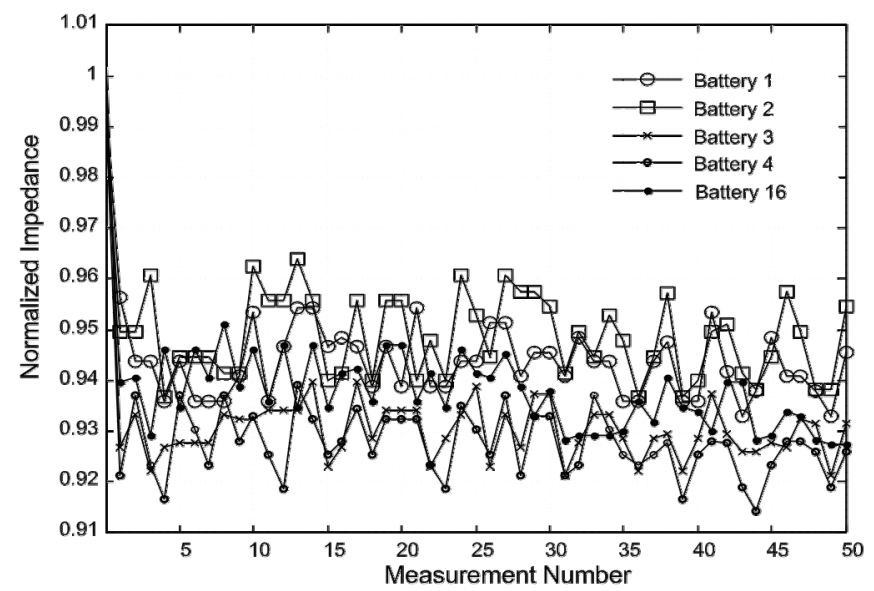

Fig. 18. Normalized impedance module.

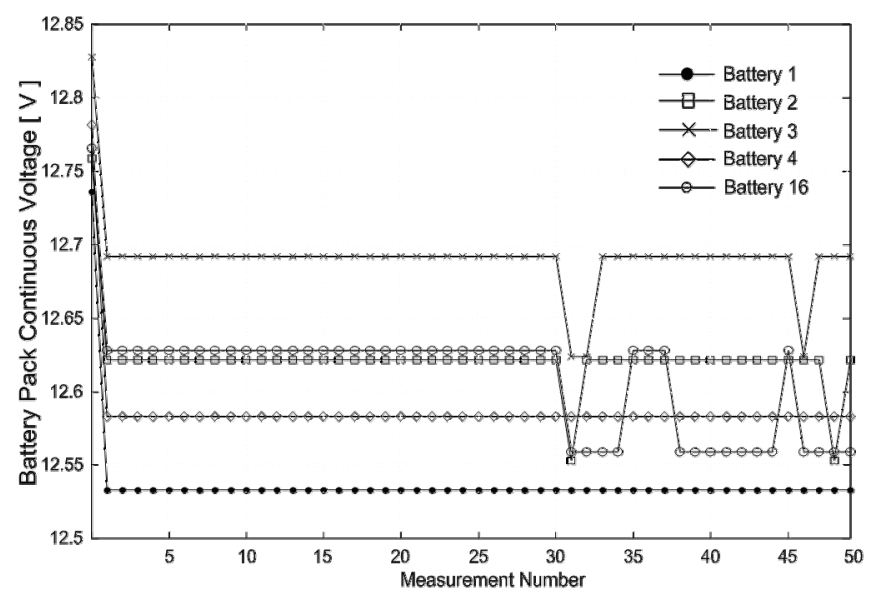

Fig. 19. DC voltage.

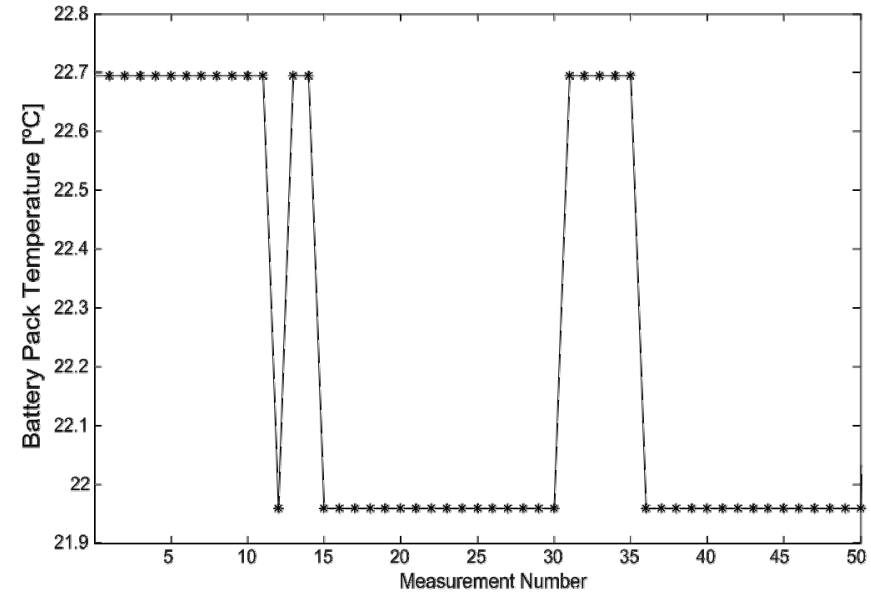

Fig. 20. Operation temperature.

\section{CONCLUSIONS}

The proposal of a battery diagnosis system integrated with the charger allows a historical record of the DC voltage, impedance, normalized impedance and temperature measurements to be obtained. This record includes all of the battery pack evaluations performed.

These data are displayed in graphs to the user, who can evaluate the batteries with the system on-line. The module graph of the normalized impedance shows directly the $\mathrm{SoH}$ of a battery, because according to the literature $[2,3,9,10,14]$, when the normalized impedance module value is above $130 \%$ of the battery reference value, the battery can be considered inadequate for use. However, it is interesting to observe the temperature in the bank during the measurements, due to the fact that the battery impedance can change with temperature, and the DC voltage, which can provide information on short circuits in the cells, short circuits in the wires of the measuring system, discharged battery and other problems.

The proposed system uses a reference value to evaluate the impedance for each battery. This value is calculated through measurements recorded for the same battery when new. This procedure is possible because the proposed system is integrated with the battery charger. The proposed strategy increases the reliability of the impedance test, because the internal impedance of batteries differs among models, capacities, construction methods and even within the same set of batteries.

The preliminary results presented herein validate the proposed battery evaluation system. Future results, with the data on the whole life cycle of the batteries, will be able to confirm the capacity of the proposed system to perform a $\mathrm{SoH}$ diagnosis of batteries.

\section{REFERENCES}

[1] "IEEE Recommended Practice for Maintenance, Testing, and Replacement of Valve-Regulated LeadAcid (VRLA) Batteries for Stationary Applications," IEEE Std 1188-2005 (Revision of IEEE Std 1188-1996), pp. 0_1-34, 2006. 
[2] J. M. Hawkins and L. O. Barling, "Some aspects of battery impedance characteristics," in Proc. of INTELEC '95, pp. 271-276, 1995.

[3] J. M. Hawkins, "Some field experience with battery impedance measurement as a useful maintenance tool," in Proc. of INTELEC '94, pp. 263-269, 1994.

[3] J. M. Hawkins, "Some field experience with battery impedance measurement as a useful maintenance tool," in Proc. of INTELEC '94, pp. 263-269, 1994.

[4] I. Damlund, "Analysis and interpretation of ACmeasurements on batteries used to assess state-of-health and capacity-condition," in Proc. of INTELEC '95, pp. 828-833, 1995.

[5] M. Coleman, et al., "State-of-Charge Determination From EMF Voltage Estimation: Using Impedance, Terminal Voltage, and Current for Lead-Acid and Lithium-Ion Batteries," IEEE Transactions on Industrial Electronics, vol. 54, pp. 2550-2557, 2007.

[6] G. Lodi, et al., "The use of impedance measurement as an effective method of validating the integrity of VRLA battery production," in Proc. of INTELEC 2004, pp. 605-610, 2004.

[7] F. J. Vaccaro and P. Casson, "Internal Resistance: Harbinger of Capacity Loss in Starved Electrolyte Sealed Lead Acid Batteries," in Proc. of INTELEC '87, pp. 128-131, 1987.

[8] M. S. Sudhan, et al., "Use of AC impedance/conductance and DC resistance for determining the reliability of VRLA battery systems," in Proc. of INTELEC '93, pp. 384-391 vol.2, 1993.

[9] G. J. Markle, "AC impedance testing for valve regulated cells," in Proc. of INTELEC '92, pp. 212-217, 1992.

[10] M. Fatima, et al., "Failure detection of stationary leadacid batteries in service in various regions of Brazil," in Proc. of INTELEC 2002, pp. 204-213, 2002.

[11] A. R. Waters, et al., "Monitoring the state of health of VRLA batteries through ohmic measurements," in Proc. of INTELEC 97, pp. 675-680, 1997.

[12] M. Kiel, et al., "Validation of single frequency $Z$ measurement for standby battery state of health determination," in Proc. of INTELEC 2008, pp. 1-7, 2008.

[13] K. Kutluay, et al., "A new online state-of-charge estimation and monitoring system for sealed lead-acid batteries in Telecommunication power supplies," IEEE Transactions on Industrial Electronics, vol. 52, pp. 1315-1327, 2005.

[14] M. Coleman, et al., "An Improved Battery Characterization Method Using a Two-Pulse Load Test," IEEE Transactions on Energy Conversion, vol. 23, pp. 708-713, 2008.
[15] M. Cugnet, et al., "On Lead-Acid-Battery Resistance and Cranking-Capability Estimation," IEEE Transactions on Industrial Electronics, vol. 57, pp. 909-917, 2010.

[16] C. R. Gould, et al., "New Battery Model and State-ofHealth Determination Through Subspace Parameter Estimation and State-Observer Techniques," IEEE Transactions on Vehicular Technology, vol. 58, pp. 3905-3916, 2009.

[17] D. Dinh Vinh, et al., "Impedance Observer for a Li-Ion Battery Using Kalman Filter," IEEE Transactions on Vehicular Technology, vol. 58, pp. 3930-3937, 2009.

[18] M. Charkhgard and M. Farrokhi, "State-of-Charge Estimation for Lithium-Ion Batteries Using Neural Networks and EKF," IEEE Transactions on Industrial Electronics, vol. 57, pp. 4178-4187, 2010.

[19] C. Ying-Chun, "High-Efficiency ZCS Buck Converter for Rechargeable Batteries," IEEE Transactions on Industrial Electronics, vol. 57, pp. 2463-2472, 2010.

[20] E. Sanchis, et al., "High-Power Battery Discharge Regulator for Space Applications," IEEE Transactions on Industrial Electronics, vol. 57, pp. 3935-3943, 2010.

[21] M. J. Hlavac, et al., "Field and laboratory studies to assess the state of health of valve-regulated lead acid and other battery technologies using conductance testing," in Proc. of INTELEC '93, pp. 375-383 vol.2, 1993.

[22] W. H. Edwards, et al., "Conductance measurements in relation to battery state of charge," in Proc. of INTELEC '99, p. 7 pp, 1999.

\section{BIOGRAPHIES}

Telles Brunelli Lazzarin was born in Criciúma, Santa Catarina, Brazil, in 1979. He received the B.S. degree in electrical engineering and the M.S. and Ph.D. degrees from the Federal University of Santa Catarina (UFSC), Florianópolis, Brazil, in 2004, 2006, and 2010, respectively.

$\mathrm{He}$ is currently a Professor in Federal Institute of Santa Catarina (IFSC). He is a member of the Brazilian Power Electronic (SOBRAEP) and a member of the IEEE Society.

Ivo Barbi was born in Gaspar, Santa Catarina, Brazil, in 1949. He received the B.S. and M.S. degrees in electrical engineering from the Federal University of Santa Catarina (UFSC), Florianópolis, Brazil, in 1973 and 1976, respectively, and the Dr.Ing. degree from the Institut National Polytechnique of Toulouse, Toulouse, France, in 1979.

He founded the Brazilian Power Electronics Society (SOBRAEP) and the Institute of Power Electronics (INEP), UFSC. He is currently a Professor with INEP and the Leader of the power electronics program of UFSC. 